\title{
The Donor Problem: An Experimental Analysis of Beneficiary Empowerment
}

\author{
by Klaus AbBinK* and Matthew Ellman** \\ * $\quad$ University of Amsterdam (CREED) \\ ** Institut d'Anàlisi Econòmica (IAE-CSIC and CREA)
}

July 2008

\begin{abstract}
Donors often rely on local intermediaries to deliver benefits to target beneficiaries. Each selected recipient observes if the intermediary under-delivers to them, so they serve as natural monitors. These recipients may, however, withhold complaints to 'thank' the intermediary for selecting them. Furthermore, the intermediary may distort selection (e.g. by picking richer recipients who feel less entitled) to reduce complaints. We design an experimental game representing the donor's problem. We compare two institutions. In one treatment, the intermediary selects recipients. In the other, selection is random - as by an uninformed donor. In our data, random selection dominates delegation of the selection task to the intermediary. Selection distortions are similar, but intermediaries divert more when they have selection power (correctly anticipating that gratitude for selection will reduce complaints). Our results identify a problem in combining selection and delivery tasks. The insights are also applicable to social funds, decentralisation and participatory projects.
\end{abstract}

\section{Keywords}

Development, Entitlement, Experiments, Fairness, Intermediaries, Monitoring, Punishment, Targeting.

\section{JEL Classification Codes}

C90, D63, O12.

\section{Acknowledgements}

The authors thank Xiaojing Kong, Lars Moller, Danila Serra, and Ping Zhang for their help in conducting the experiment. Thanks to Robin Hogarth, Rosemarie Nagel, Paul Pezanis-Christou, Elke Renner, and seminar participants in Amsterdam for helpful comments and suggestions. Financial support from the Nuffield Foundation, the British Academy, the University of Nottingham and the Spanish Ministry of Science and Technology (BEC 2003-00412 and a Ramon y Cajal fellowship) is gratefully acknowledged. Part of this research has been carried out while Abbink was a visitor at the Institut d'Anàlisi Econòmica (CSIC), Barcelona. He gratefully acknowledges their hospitality and support.

\section{Authors}

\begin{tabular}{ll}
\hline Klaus Abbink & Matthew Ellman \\
\hline CREED & Institut d'Anàlisi Econòmica (CSIC) \\
Amsterdam School of Economics & Campus UAB \\
Roeterstraat 11 & Bellaterra \\
1018 WB Amsterdam & 08193 Barcelona \\
The Netherlands & Spain \\
Phone +31-020-5254229 & Phone +34-93-5806612 \\
Fax +31-020-5255283 & Fax +34-93-5801452 \\
$\underline{\text { k.abbink@uva.nl }}$ & matthew.ellman@iae.csic.es \\
\hline
\end{tabular}




\section{Introduction}

Donor organisations rely on intermediaries to deliver benefits, and they often turn to the same intermediaries for help in identifying and selecting suitable beneficiaries. The case of an international NGO (unnamed for confidentiality) that donates money to buy goats for poor families in Honduras is typical. This donor engaged local leaders to act as intermediaries. Their main task was to organise the purchase and delivery of goats, but the donor also entrusted these leaders with the task of selecting target beneficiaries, because the leaders had more information than the donor for identifying the poorest families in their villages. In this paper, we analyse the effect of allocating the two tasks to the same agent.

Targeting is a central issue in development projects. Resource limitations pressure donors (be they governmental or non-governmental organisations) to identify and direct benefits to those most in need; the benefits might be schoolbooks, vouchers, food and shelter for disaster relief, healthcare and medicines, seeds and training as agricultural support, or even money. The literature on targeting highlights the dilemma of whether to involve local leaders whose informational advantage may be offset by conflicting interests. ${ }^{1}$ Experts also emphasise the risk that local leaders derive power from their role in selection.

In this paper, we motivate and investigate two specific concerns: (1) selection powers may make an intermediary less reliable in project delivery; (2) delivery powers may create a conflict of interest in the selection task. To the best of our knowledge, we are the first to set up an experimental model of the donor's selection-and-delivery problem. So our goal is exploratory. If combining the selection and delivery tasks increases the level of total distortions in a laboratory setting, then it makes sense to bear the costs of analysing whether combining selection and delivery tasks has a similar effect in the field. By adopting a simple game-theoretic representation of this donor problem, we also hope to clarify exactly how combining selection and delivery tasks under a common agent can exacerbate the agency problems in each task.

While some intermediaries are altruistic individuals who share the donor's aims, others may be tempted to divert resources to their personal benefit. This leads to two types of distortion: intermediaries may select the "wrong" (non-needy) beneficiaries and they may divert the donor's resources to themselves instead of the selected beneficiaries. The donor's problem is to limit these distortions in selection and delivery. The goat-donor NGO in the above example suffered from significant distortion of both types. A follow-up study of this project (see Ketzis (1997)) revealed that some local leaders had selected beneficiaries who were among the richest in their village, and many leaders had diverted benefits to their relatives (a form of embezzlement).

\footnotetext{
${ }^{1}$ See Jaspars and Young (1995: 92-93) for evidence from a typical best practice guide, and Galasso and Ravallion (2005) for an economic model where donor and intermediary have different distributive goals.
} 
Because it is very costly for the donor to investigate whether the intermediary is misappropriating funds (embezzling), donors only mount investigations after receiving strong signals of foul play. The selected recipients are natural monitors of the intermediary, because each recipient automatically observes what the intermediary delivers to her. In fact, it is now common practice for NGOs to inform selected beneficiaries of what they can expect to receive and to ask them to complain if the intermediary does not deliver as much as promised.

Unfortunately, beneficiaries do not always complain about foul play. Three key factors frequently explain this reticence: costs of complaining, distinct norms of justice and reciprocity (e.g. from feelings of gratitude). The costs of complaining may be material (e.g. the intermediary may retaliate) or psychological (e.g. a feeling of disloyalty to the intermediary). Distinct norms are common - the villagers may consider it reasonable for the intermediary to appropriate funds that the donor intended for the villagers. ${ }^{2}$ Gratitude - the desire to reciprocate kind behaviour - also inhibits complaints; villagers may feel thankful to the intermediary for benefits even if less than the donor intended.

In this paper, we focus on reciprocity motives (like gratitude) as a cause of reticence. Consider the incentives of a local intermediary, such as a village leader in the above goatintroduction project. When he selects among potential beneficiaries, he knows that the donor wants him to pick poorer families, but richer families, being illegitimate recipients, may feel more grateful to him. If purely self-interested, he would pick rich beneficiaries, since their gratitude makes them less likely to complain. This way, he can divert more funds to himself. So not only do the benefits go to the wrong people, but the beneficiaries also receive less.

How can these negative consequences be alleviated? One alternative is to separate the tasks of selection and delivery. Indeed, NGOs often send their own representative to select beneficiaries, delegating only the delivery task to a local intermediary. This has been criticised on the grounds that representatives cannot become as informed as the local intermediary, so they are bound to pick some richer households as beneficiaries by mistake. In the worst case, separate selection (by representatives) is equivalent to random selection, but the opportunistic local intermediaries just described would pick richer families on purpose. So for high levels of opportunism, even if separate selection were fully random, it could be less distorted than selection by the informed intermediary.

The selection method can also affect the gratitude of a given beneficiary. Under selection by intermediaries, beneficiaries may feel grateful to the intermediary simply for selecting them. By contrast, under separated (or random) selection, any gratitude is directed at the representative (so it does not interfere with the beneficiary's willingness to complain). So we conjecture that beneficiaries complain more often when selection is separated. Provided intermediaries anticipate this effect, they will divert less.

\footnotetext{
${ }^{2}$ Indeed, in Platteau and Gaspart's (2003) case study, villagers were so angry when the donor sanctioning the leader for embezzling project funds that they punished the few villagers who had complained to the donor.
} 
In the light of these two possible benefits, we conjecture that even when separated selection is equivalent to random selection, this selection method is often superior to selection by the intermediary. In this paper, we put this conjecture to a test. We design a laboratory experiment that captures the essential features of the donor problem in a stylised game. The experimental approach allows us to compare the two institutions (random versus intermediary selection) in a controlled environment. Our model involves one intermediary and four villagers, two of them "rich" and two of them "poor". The intermediary allocates a sum of money (the donated funds) to two of the villagers (the target beneficiaries), and keeps the remainder for himself. There are two treatments: in the Intermediary Selection (IS) treatment, the intermediary also selects the target beneficiaries; in the Random Selection (RS) treatment, this selection is random. A villager who is allocated too little by the intermediary can file a costly complaint. This triggers an investigation, and the embezzling intermediary is penalised. With this experimental set-up, we can compare the performance of the two institutional designs in terms of selection distortion and levels of embezzlement. Further, we can identify the behavioural effects on which we based our conjectures.

In our results, rich villagers do indeed complain less than poor villagers. The selection method also matters: rich villagers tend to complain more under random selection than under intermediary selection. Our results about intermediary behaviour are partly in line with our conjectures. A substantial number of intermediaries choose to give to rich villagers, despite a strong countervailing pressure from fairness motivations favouring the poor. The selection distortion in our data is roughly the same as under random selection. Our results on embezzlement under the two selection institutions strongly corroborate our predictions. Embezzlement is clearly lower under random selection: intermediaries allocate almost $60 \%$ more to the villagers when they do not have the power to select. Overall, in our experiment, poor villagers are better off under random selection, so separating the selection from the delivery task helps the donor achieve its objectives.

These results are relevant for a broader range of issues. Our framework also applies when states (and supra-national bodies such as the European Union) set up "Social Funds" to finance projects designed and proposed by NGOs. Here, project design determines the potential beneficiaries (e.g. a new school most benefits families living close to the proposed site). So, an NGO that wins resources from a Social Fund acts as intermediary in the effective selection of target beneficiaries as well as in the delivery of benefits (project implementation).

Distorted selection is a major topic in the analysis of bureaucracy and decentralisation. Shleifer and Vishny (1993) show that corruption is particularly damaging when it distorts the allocation of economic resources. In Banerjee (1997), governmental red tape serves to prevent bureaucrats from selecting the rich in place of the needy. Our results suggest that it may instead be optimal to entirely remove selection power from bureaucrats who can embezzle resources. Our analysis directly applies to the question of decentralising selection tasks to the 
local intermediaries who manage the delivery task. Bardhan (2002) summarises existing empirical and theoretical work on how decentralisation affects distortions in selection. ${ }^{3}$

Our analysis is closely related to the topic of empowerment. Development practitioners and theorists have long argued that villagers only stand up for their rights when they feel entitled to benefits, (see Chambers (1983), Chabal and Daloz (1999), Platteau and Abraham (2002), World Bank (2002), and Reinikka and Svensson (2005)). ${ }^{4}$ If villagers feel less entitled to make demands on the intermediary when the intermediary selects recipients, removing this selection power may help to empower villagers.

Grass-roots participation is central to the community-based approach that has recently gained currency in the world of development (e.g. see Chambers (1983) and World Bank (1996)). In its ideal form, every villager is an "intermediary" as well as recipient, but in practice such projects often suffer from "capture" by an elite. ${ }^{5}$ Capture makes our analysis relevant, because the elite effectively becomes the intermediary.

The paper is organised as follows. Section 2 reviews the related literature. In section 3 we describe the experimental model and procedures. Section 4 outlines our hypotheses. The results of the experiment are presented in section 5. Section 6 summarises and concludes.

\section{Related experimental literature}

There is no experimental study of our donor problem in a development context, but our set-up relates to a range of prior experiments. Since our game involves costly punishment, the large literature on the ultimatum game is relevant to our study. In this game, introduced by Güth, Schmittberger and Schwarze (1982), the proposer suggests a division of a cake to the responder. If the responder accepts, the division is implemented; if he rejects, neither receives anything. Subgame perfect equilibrium predicts that the responder accepts any positive offer. Foreseeing this, the proposer offers virtually nothing, and the responder accepts. The experimental evidence strongly refutes this prediction. Responders reject substantial amounts of money, while proposers make positive offers (often half of the cake). The rich evidence from the ultimatum game - see Camerer (2003) for a recent survey - leads us to expect that in our game villagers will generally be willing to engage in costly complaints. ${ }^{6}$

\footnotetext{
${ }^{3}$ See also Wade (1982), Fuentes (1996), Tendler (1997) and Bardhan and Mookerjee (2005).

${ }^{4}$ Prendergast (2002 and 2003) shows how difficult it is to use complaints from recipients in bureaucratic and consumer settings. However, in his theory, "monitoring from below" leads the "intermediaries" to over-allocate resources, because the resources are public and he implicitly rules out embezzlement.

${ }^{5}$ See Bardhan and Mookherjee (2000), Bierschenk, de Sardan and Chauveau (2000), Conning and Kevane (2002), Platteau and Gaspart (2003) and Reinikka and Svensson (2004).

${ }^{6}$ More recently, costly punishment has become a popular research issue in the context of public good games. In standard public good games, each subject in a group of $n$ persons can decide to invest an amount $x$ (up to some limit) in a public good. Everybody in the group of $n$ individuals receives a return of $c x$, where $c<1$, but $n c>1$. It is then a dominant strategy for rational players to not invest, but the Pareto efficient solution requires everybody to cooperate by investing the maximum. Experimental evidence (see, e.g. Keser and van Winden
} 
Extensions of the ultimatum game beyond the one-to-one encounter, as is vital for any model of the donor problem, are surprisingly rare. Okada and Riedl (1999) give the proposer the choice to divide either a small cake between himself and one responder, or a larger cake between himself and two responders (both having veto power). Despite being Paretodominated and unequal (in that one person never receives anything), many proposers choose the small pie, single responder option. Güth and van Damme (1998) add a dummy player (who can receive but has no veto power) to the standard ultimatum game under various informational conditions. The dummy typically gets nothing. Like ours, these papers look at costly punishment in a multi-player game, but neither investigates the impact of how responders are selected.

Brandts, Güth, and Stiehler (2006) do look at player selection effects. In their game, the first mover, given information from personality questionnaires, chooses to which of two players to delegate the power to divide a cake. The authors find that allocators selected in this way allocate more to the first movers than those in a random selection control. This hints at some form of gratitude (also a focus of our work), but since their game does not allow for punishment, the environment they study is fundamentally different from the donor problem.

Most akin to our study is the recent work by Barr, Lindelöw, and Serneels (2003). ${ }^{7}$ These authors also address the problem of embezzlement in service delivery in developing countries. They focus on the effect of wages, effort observability, professional norms and the rules for assigning a monitor. In their game, the intermediary decides how much to embezzle and the monitor chooses how much to spend on monitoring the intermediary. The experimental subjects are Ethiopian nursing students. The authors find that intermediaries embezzle less when their wages increase, when the risk of being caught rises, and when they face an elected rather than a randomly selected monitor. In contrast with our setting, the recipients themselves neither monitor nor complain (recipients do not observe any signals of embezzlement). Furthermore, the intermediary does not select the recipients, so the problem of distorted selection does not arise.

These papers shed some light on our topic, but they look at very different set-ups. So their results cannot answer our research questions. A new experiment needs to be designed.

\section{The model and the experimental design}

\subsection{The model}

We designed a maximally simplified experimental model that still captures essential features of the real-life donor problem and allows us to test the above conjectures. Given our focus on

(2000)) finds positive, but declining contributions. Fehr and Gächter (2000) introduce a costly punishment opportunity. This raises contributions and the decline disappears.

${ }^{7}$ See also the small, but growing literature on corruption experiments, e.g. Frank and Schulze (2000), Abbink, Irlenbusch, and Renner (2002), and González, Güth, and Levati (2002). 
the interaction between the intermediary and the villagers, we decided not to include the donor as an active player. This allowed us to design a two stage game with the intermediary as the first mover and four villagers as second movers.

The first mover's delivery task is to allocate an amount of 100 talers (the fictitious experimental currency) to two of the four second movers. This amount represents the donation from the simulated donor. The first mover can allocate less than 100 talers to the second movers, because he can keep any remainder for himself - this self-allocation represents embezzlement.

The four second movers, labelled S1, S2, S3, and S4, play the role of the villagers receiving the donation. ${ }^{8}$ At the outset of the experiment, each player has an endowment. The second movers S1 and S2 have an endowment of 0, while S3 and S4 are initially given an amount of 50. So we refer to S1 and S2 as the "poor" (needy) villagers, and to S3 and S4 as the "rich" (less needy) second movers. The first mover also starts with an endowment. He is initially endowed with 100 talers, making him the richest of all players. This reflects the fact that in real-life situations the intermediary is typically a powerful and relatively wealthy person in the village. (Note that these 100 talers include any salary from the donor.) All players know the distribution of endowments and the first mover knows the endowments of the second movers.

The first mover makes one or two decisions, depending on the treatment. In the IS (intermediary selection) treatment, he selects exactly two of the second movers as being "active". In the RS (random selection) treatment, this decision is omitted and the active second movers are selected at random (with equal probability); this captures the extreme case of selection by an uninformed representative of the donor). In both treatments the first mover divides an amount of 100 (which he receives in addition to his endowment) between the two active second movers and himself; he can allocate up to 50 talers to each second mover.

At the second stage of the game, each of the active second movers decides whether or not to file a complaint against the first mover. An active second mover can file a complaint if she has received less than 50 talers. If an active second mover has received the full 50 talers, then she cannot complain. This reflects the donor's intention that the intermediary should allocate the full 50 talers to each of the active second movers. ${ }^{9}$

A complaint inflicts a cost of 10 talers on the second mover who files it. This arrangement captures a situation in which negative consequences outweigh possible gains from complaining. These negative consequences could be hassle costs from filing a complaint, or a

\footnotetext{
${ }^{8}$ The choice of two villagers of each type results from a trade-off between realism and practicality. The smallest number of second movers with which we could model the situation would be two, one of each type. We chose a larger number to be closer to the village scenario; exceeding four would have implied an excessive resource cost.

${ }^{9}$ To avoid suggestive wording in the instructions, we did not explicitly label self-allocation as embezzlement.
} 
negative reputation within the village as an informer. Gains may include some compensation of the complaining villager by the donor, but these are typically smaller. ${ }^{10}$

In the case of a valid complaint, an investigation is carried out and the first mover is caught (with certainty, for simplicity). As a penalty, the first mover's final payoff is reduced to 50 talers, independent of how much he has embezzled (i.e., he loses 50 talers plus all the talers he allocated to himself). This punishment can be interpreted as a fine or a reputational cost.

Second movers cannot complain about not being selected. This reflects the assumption that the donor cannot identify who is needy and who is not, even with a costly investigation. In fact, inactive second movers can never file a complaint, not even on behalf of the active second movers. This makes sense, because second movers only observe their own allocations, so inactive second movers cannot detect embezzlement. ${ }^{11}$

In the experiment, subjects play the game only once. This captures a scenario in which the donor makes a single donation to a given village (e.g. giving out food as disaster relief or text books for schooling), or implements a project that is a one-off in nature (e.g. building a school). ${ }^{12}$ The choice of the one-shot environment ensures that repeated-game effects do not interfere with the gratitude effects we seek to isolate in this paper.

\subsection{The conduct of the experiment}

The experiment was conducted at the Centre for Decision Research and Experimental Economics (CeDEx) of the University of Nottingham. Subjects were recruited by e-mail from a database of students, who had previously registered at CeDEx as potential participants in experiments. Each subject was allowed to participate in only one session, and no subject had participated in experiments similar to the present one. The subjects were undergraduate students from a wide range of disciplines. Virtually all subjects were aged between 19 and 25, with a balanced gender distribution. ${ }^{13}$

\footnotetext{
${ }^{10}$ It is difficult to solve the donor problem by making (valid) complaints profitable. First, the intermediary can increase threats in response to higher rewards. Second, high rewards may induce invalid complaints. We represented the complaint costs by a lump-sum (10 talers) to simplify the rules of the game.

${ }^{11}$ Empirically, individuals tend only to be asked to report on personal receipts (see e.g. Olken's (2006) analysis of rice redistribution). Another reason is that emotions, like jealousy, can distort reporting on others' receipts.

12 Platteau and Gaspart (2003) note that, aiming for sustainability, some donors intentionally avoid repeat funding of projects to force financial independence of the village after the initial donation of seed money.

${ }^{13}$ We ran a standard lab experiment with students, rather than villagers in a developing country, because this well-established technique allows optimal control of the experimental environment. This is particularly important, as the game has not been run before. Our results might be affected by this choice of subject pool. Note, however, that we focus on the comparison of treatments, so our conclusions are not sensitive to the possibility of magnitude effects (Roth, Prasnikar, Okuno-Fujiwara, and Zamir (1991), Brandts, Saijo, and Schram (2004)). Related experiments conducted in developing countries are reported e.g. in Henrich, Boyd, Bowles, Camerer, Fehr, Gintis, and McElreath (2001), Barr and Kinsey (2002), and Humphrey and Verschoor (2004); Oosterbeek, Sloof and van de Kuilen's (2004) meta-analysis find that ultimatum game tendencies vary geographically, but mostly rule out cultural trait explanations.
} 
First movers and second movers were told to go to separate lecture theatres by email. This measure increases anonymity since first and second movers did not see each other. ${ }^{14}$ Participants were not allowed to communicate and we ensured that the distance between subjects was sufficient to prevent them from influencing each other's decisions - the lecture theatre for the second movers had a capacity of 120 seats, so there was much empty space between participants (laboratory-style visual separation of participants was not possible).

Each play consists of the first mover's selection and allocation decision and the active second movers' complaint decision. To gather a rich data set, we decided to elicit complete strategies from the second movers rather than decisions on a particular node of the game. ${ }^{15}$ Second movers therefore had to decide, before learning the first mover's decision, on a minimum acceptance level. This was the threshold below which they would file a complaint if they were selected as active second movers. ${ }^{16}$ If we had used the traditional approach to let participants play the game move by move, data on complaints would only be available for the specific allocations actually observed in the experiment. Treatment differences might then have been impossible to detect.

Each second mover had to make this decision for both treatments of the experiment, i.e. specify one number for the case in which the intermediary selects her as active, and one number for the case in which she is selected randomly. This "second-level" strategy elicitation gives us a direct comparison between the two treatments in terms of complaint behaviour. ${ }^{17}$ It also doubles the number of independent observations we obtain from the same number of participants.

Sessions started at the same time for first and second movers. Two research assistants (one in each room) read aloud the instructions, which were the same for first and second movers, and for both treatments of the game. The instructions were context-free, making no reference to

\footnotetext{
${ }^{14} \mathrm{We}$ aimed to have four groups of five players for each session (i.e. four first movers in one room and 16 second movers in the other room). Due to variation in the show-up rates, the actual number of groups ranged from two to five.

${ }^{15}$ This is a simplified version of the strategy method proposed by Selten (1967). It is sometimes argued that the elicitation of complete strategies triggers "cold" decisions that may be different from the "hot" decisions made when reacting to an act actually carried out by a previous mover. If this were the case, we would expect less emotional reactions, reducing our ability to identify the treatment effects. Against this potential downside of the strategy approach, we have a clear upside: the data become so much richer that even very subtle effects can be detected. Evidence for substantially different behaviour triggered by the two methods is sparse. Brandts and Charness (2000) examine behaviour in different interactive games comparing spontaneous play and complete strategy elicitation, but find results to be unaffected. They suggest that both procedures are equivalent for lowcomplexity tasks. Abbink and Pezzini (2005) also use both methods; they do not find any effect reversed, but identify significant effects in the strategy data that are not detectable with spontaneous play.

${ }^{16}$ Implicitly we restrict the second movers to monotone strategies. It seems implausible that many second movers would have strategies that prescribe a complaint for one offer and no complaint for a lower one.

${ }^{17}$ We also conducted pilot sessions using only one variant. Though data are too sparse to apply a meaningful statistical analysis, the results look encouragingly similar.
} 
the development scenario we model. ${ }^{18}$ The written instructions are reproduced in appendix B. After reading out the instructions, the assistants handed out the decision sheets. The first movers' decision sheets told them which treatment they were playing. In the RS treatment, the active second movers were preselected by a random process that made selection of each combination of two second movers equally likely. In the IS treatment, first movers had to tick boxes indicating the two second movers they wished to select.

When all participants had made their decisions, their decision sheets were collected, and the experimenter calculated and filled in a results sheet for each participant. While waiting for the results, the subjects filled in questionnaires asking about their reasoning. The questions are reproduced in appendix $\mathrm{C}$.

Each session lasted approximately 45 minutes; this includes the time spent to read the instructions. At the end of the experiment, subjects were paid their total earnings anonymously in cash, at a conversion rate of one pound sterling for 10 talers. To guarantee a minimum payment of $£ 3$ (as promised in the invitation emails) we granted a show-up fee of $£ 4$. In the worst case, a poor second mover who was allocated nothing and complained would make a loss of $£ 1$ from play, achieving a take-home payoff of $£ 3$. Subjects earned between $£ 3.50$ and $£ 20.50$ with an average payoff of $£ 9.15$ and a mode of $£ 9$, which are considerably above the typical student wage in Nottingham. At the time of the experiment, the exchange rate to other major currencies was approximately US- $\$ 1.80$ and $€ 1.50$ for $£ 1.00$.

We conducted four sessions with each treatment. This allowed us to gather data from 15 first movers in each treatment (IS and RS) and 60 second movers in each role (rich or poor). Notice that second movers play both treatments at the same time. Since the game is one-shot and simultaneously played, we can treat each individual as an independent observation. Our controlled environment allows us to base our statistical analysis entirely on nonparametric tests performed on these data points.

\section{Hypotheses}

An obvious benchmark hypothesis can be derived from a game theoretic analysis of our model. If all the actors are fully rational own-payoff maximisers, the second movers never complain, as it is costly. Anticipating that nobody will complain, the first mover always embezzles the whole pie, and in the treatment where the intermediary selects (IS), is indifferent between selecting rich and poor beneficiaries. So all second movers end up with only their endowment, and the selection institution has no impact.

\footnotetext{
${ }^{18}$ Evidence for the effects of instruction framing has been mixed so far. In a tax evasion experiment, Baldry (1986) finds far more evasion if the task is presented neutrally as a gambling opportunity, but Alm, McClelland, and Schulze (1992) find no differences. Burnham, McCabe, and Smith (2000) find significantly less trusting choices in a reciprocity game when players are called "opponents" instead of "partners". On the other hand, Abbink and Hennig-Schmidt (2002) do not find significantly different behaviour between a neutrally and a naturally worded version of the bribery experiment by Abbink, Irlenbusch, and Renner (2002).
} 
Hypothesis H0. Second movers never complain. First movers are indifferent between selecting rich and poor second movers in IS and they keep the whole pie in both treatments.

A large body of previous experimental evidence, e.g. from the ultimatum game, suggests that this outcome is unlikely. Norms of fairness tend to motivate significant complaining. On the other hand, feelings of gratitude may inhibit complaints. We focus on the interaction between these two effects. There are two reasons to expect more complaints from poor than rich second movers. In both treatments, the poor are likely to be more demanding, because (having no endowment) they feel needier. Further, in the IS treatment, the poor second movers may feel grateful when selected by the intermediary, but rich second movers, being less entitled to selection, have more reason to feel grateful. All standard norms of fairness dictate that the first mover should select the poor, not the rich, second movers. ${ }^{19}$

Hypothesis H1. Rich second movers complain less than poor ones, i.e. their complaint thresholds are lower. This difference is greater in the IS treatment.

Notice that gratitude for selection (and related reciprocity motives) can only inhibit complaints when directed at the intermediary, as in the IS treatment; in the random selection (RS) treatment, there is no such effect. So we predict that second movers (especially the rich) will complain less in IS than in RS. (This prediction contrasts with that of consequentialist models of fairness (such as Fehr and Schmidt's (1999) inequality aversion model) where second mover strategies would be independent of the selection treatment, since selected second mover payoff choices are the same in either treatment.)

Hypothesis H2. Second movers complain less in IS than in RS, i.e. their complaint thresholds are lower.

Gratitude and reciprocity might just shift in the opposite direction, because second movers might feel that the first mover is less responsible for final outcomes when selection is random - the first mover has less overall control in RS. This "responsibility-alleviation" 20 effect applies more strongly to poor than rich second movers, because the rich expect little from the intermediary even where perceived as fully responsible. It implies:

Hypothesis H2'. Second movers complain more in IS than in RS, i.e. their complaint thresholds are higher.

Turning our attention to the intermediaries, we can formulate two countervailing hypotheses. If an opportunistic first mover thinks that the rich complain less than the poor (as in hypothesis H1), then he selects the rich so that he can get away with more embezzlement.

\footnotetext{
${ }^{19}$ Defining kindness of an action as giving more than demanded by societal norms and applying, for instance, the formal reciprocity model of Cox, Friedman and Sadiraj (2008) immediately generates these predictions.

${ }^{20}$ Charness (2000) introduced this term to denote how "a shift of responsibility to an external authority dampens internal impulses towards honesty, loyalty, or generosity." In our case, a shift in responsibility for selection (away from the intermediary) dampens the second movers' tendency to hold the intermediary responsible for delivery (which the intermediary always controls).
} 


\section{Hypothesis H3. First movers select the rich second movers.}

The counter-hypothesis is that first movers are predominantly motivated by fairness considerations and wish to give to the poor because they are more needy. ${ }^{21}$

\section{Hypothesis H3'. First movers select the poor second movers.}

We are also interested in how much the intermediaries deliver. If an opportunistic first mover thinks that second movers complain less in IS than in RS (as in hypothesis H2), then he will embezzle more in IS.

\section{Hypothesis H4. First movers allocate less to second movers in IS than in RS.}

Note that there is another reason why first movers might allocate more on average in RS than IS. In IS, an opportunistic first mover can always pick the rich, whereas in RS he is sometimes forced to allocate to a poor second mover. If he thinks the poor complain more (as in H1), he therefore allocates more on average in RS (even if he does not believe H2).

\section{Results}

We summarise the relevant data in this section, but the reader can also find the raw data in appendix A: Tables A1 and A2 show the participants' decisions in the two treatments of our experiment. Each row stands for one matching. The first column depicts the session number. The second column indicates the number of the (up to five) first movers of the session. Columns 3 and 5 depict the active second movers - selected by the first mover in IS, and randomly drawn in RS. Columns 4 and 6 show how much the first mover allocated to these second movers. The remaining columns depict the decisions made by the four second movers of the game, i.e. the thresholds chosen for the treatments with intermediary selection (IS) and random selection (RS).

It is immediately clear that first movers give allocations substantially above zero, the amount predicted by the selfish subgame perfect equilibrium (hypothesis H0). In fact, a zero allocation does not occur once in our data. Second movers' thresholds are also typically positive, though we do observe a threshold of zero in 62 out of 240 cases (25.8\%). Overall, we can conclude, as expected, that the data refute hypothesis $\mathrm{H} 0$.

Observation 0. First movers' allocations are strictly positive in all cases and second movers' complaint thresholds are strictly positive in a majority of cases. So HO is not supported.

\footnotetext{
${ }^{21}$ The experimental literature contains abundant evidence on fairness considerations, albeit mostly from twoplayer settings. In dictator games, for instance, one player (the sender) is asked to divide a cake between himself and another person. Though the receiver has no way of responding, senders tend to allocate substantial amounts to them, often up to an equal split of the pie (see Camerer (2003) for an overview). The equal split is also a very prominent outcome in many other experimental games, like the ultimatum game (Güth, Schmittberger, and Schwarze (1982), or the investment game (Berg, Dickhaut, and McCabe (1995). Scholars have recently begun to develop behavioural models that formalise inequality aversion, see e.g. Bolton (1991), Fehr and Schmidt (1999), Bolton and Ockenfels (2000), Charness and Rabin (2002), and Cox, Friedman, and Gjerstad (2007).
} 


\subsection{Gratitude of rich versus poor second movers}

Our hypothesis H1 states that the rich second movers are less likely to complain. So we should observe lower (i.e. more lenient) thresholds for complaints among the rich second movers (S3 and S4) than among the poor ones (S1 and S2). The average thresholds, computed from the entries in tables A1 and A2, are listed in table 1. (For second movers, we can pool the data from both tables because they did not know which treatment would be played.)

Table 1. Average complaint thresholds

\begin{tabular}{lccc}
\hline & IS & RS & Overall \\
\hline Poor (S1, S2) & 26.6 & 26.8 & 26.7 \\
Rich (S3, S4) & 17.8 & 22.2 & 20.0 \\
\hline Overall & 22.2 & 24.5 & 23.4 \\
\hline
\end{tabular}

Fisher's two-sample permutation test ${ }^{22}$ rejects the null hypothesis of equal thresholds (for rich and poor) at a significance level of $\alpha=0.05$ (one-sided). This holds for both treatments.

The average figures suggest that the difference is greater in the IS treatment, as hypothesis $\mathrm{H} 1$ predicts. The difference between the thresholds of the rich and the poor is almost twice as large. To assess statistical significance, we need a different test method, because all subjects played both treatments and observations from IS and RS are therefore not independent. To solve this problem, we look at those subjects whose thresholds differ by treatment. Table 2 shows, for each of the two roles (poor and rich), how many subjects submitted (a) higher, (b) lower, (c) equal thresholds in RS compared to IS.

Table 2. Within subject comparisons of thresholds across treatments

\begin{tabular}{lccc}
\hline & \multicolumn{3}{c}{ Number of subjects whose threshold is: } \\
& Higher in RS & Lower in RS & Equal in RS and IS \\
\hline Poor (S1, S2) & 13 & 20 & 27 \\
Rich (S3, S4) & 18 & 8 & 34 \\
\hline
\end{tabular}

In table 2 we can see a tendency towards higher thresholds in RS among rich second movers, and a contrasting tendency towards lower thresholds in RS among poor second movers. We apply Fisher's exact test to the first two columns of table 2 to check whether this sharp contrast (20 vs 13 as compared with 8 vs 18 ) is statistically significant. The test rejects the null hypothesis at the one-sided 5\% level. This confirms that the effect of lower thresholds

\footnotetext{
${ }^{22}$ This test is a non-parametric alternative to the t-test. For a discussion of the power of this test see Moir (1998).
} 
among rich second movers is indeed more pronounced in IS. Taking this result together with the generally lower thresholds for the rich, we find strong support for H1. ${ }^{23}$

Observation 1. Rich second movers are less likely to complain than poor second movers, and this effect is greater in RS. This supports H1.

\subsection{The effect of selection on gratitude}

For the treatment comparison of second mover complaint behaviour we had formulated two competing hypotheses. Hypothesis $\mathrm{H} 2$ led us to expect higher thresholds under random selection, as second movers then feel less grateful to the first mover. Hypothesis H2' led us to expect the opposite, namely lower thresholds under random selection, as second movers then perceive first movers as less responsible.

The previous analysis of the data from table 2 allows us to test these hypotheses as well. Recall that we observe 18 rich second movers who choose a higher threshold under RS than under IS, while only eight of them exhibit lower thresholds under RS. According to the binomial test this difference is significant at $\alpha=0.05$ (one-sided). Thus we find some evidence in favour of $\mathrm{H} 2$ in our data.

Observation 2a. Rich second movers tend to have higher complaint thresholds under RS than under IS. Hypothesis H2 is supported for rich second movers.

The questionnaire responses point to increased gratitude among the rich in IS, as the main cause of this difference. For instance, one subject chose a zero threshold (in her words) "as I wanted to 'thank' the first mover for choosing me by not fining them." Some poor also reported increased gratitude in IS (e.g. "if I have been chosen...I wouldn't want to be nasty"), but there is no systematic support for $\mathrm{H} 2$ in the decisions of the poor. The tendency we found towards higher thresholds in IS (20 subjects versus 13 in the opposite direction) is not significant. Nevertheless, it does suggest that for poor second movers, the countervailing force behind $\mathrm{H}_{2}$ ' is at least as strong as the force motivating $\mathrm{H} 2$.

Observation 2b. For poor second movers, a significant difference between complaint thresholds in the two treatments cannot be detected.

Note that we expected hypothesis $\mathrm{H} 2$ to be stronger for the rich second movers and $\mathrm{H} 2$ ' stronger for the poor ones. The questionnaires provide some anecdotal evidence for the responsibility alleviation effect that motivated $\mathrm{H}_{2}$ '. One poor second mover explained that she had chosen a lower threshold in RS than IS because in the "random [case] the first mover has less responsibility to be fair". Another felt a need to give the first mover "more leeway" in RS. Two others implicitly took the related view that things are more personal in IS than RS -

\footnotetext{
${ }^{23}$ Further support can be found in the post-experimental questionnaire. For instance, one rich second mover explicitly wrote: “....as I have some endowment I didn’t see any point in being greedy.”
} 
one mentioned a "vengeance" motive in IS (and not in RS), while the other felt the first mover should give more in IS, because he had "specifically chosen me". ${ }^{24}$

\subsection{The distorted selection effect}

We now turn our analysis to the behaviour of first movers. According to hypothesis H3, intermediaries will frequently select the rich second movers, expecting them to complain less. The counter-hypothesis H3' predicts the opposite: Fairness considerations lead first movers to select the poor. In our data, we find approximately equal support for both hypotheses. Five of the fifteen first movers select both rich second movers, while six of them choose the two poor ones. Four intermediaries choose one of each kind (the questionnaires suggest that this mixing choice stems from indifference, e.g. stating it was a "random choice").

The questionnaire reveals that most instances of distorted selection are indeed, as argued in our motivation for $\mathrm{H} 3$, due to the expectation that rich second movers would be less likely to complain. For instance, one first mover said that he chose the rich "because they already had an allocation of money and so seemed less likely to complain". The questionnaires also supported the view behind H3' that inequality aversion is a strong behavioural force: First movers who chose the poor were indeed motivated mainly by fairness considerations (one wrote, "I chose S1 and S2 because they didn't have an endowment so I felt sorry for them" and another one explained the same choice as a way "to let them at least have something"). ${ }^{25}$

Observation 3. Rich second movers are about as likely to be selected in IS as poor second movers. So we find as much support for H3 as for H3'.

It is interesting to compare selection distortion under intermediary selection with the benchmark of random selection. Under random selection, a rich second mover is selected half of the time. Under intermediary selection, this fraction could be higher or lower, depending on the relative strength of fairness and opportunism motivations. In our experiment, selection by intermediaries is almost as distorted as random selection. The first movers select altogether 16 poor second movers and 14 rich ones. This is statistically indistinguishable from the performance of random selection.

\subsection{Does random selection reduce embezzlement?}

As we have seen, random selection does not fare significantly worse in selecting the needy second movers than selection by intermediaries. The second aspect that defines the

\footnotetext{
${ }^{24}$ There is an alternative explanation why poor second movers might complain less under random selection. When the intermediary selects, a poor second mover may (feeling entitled to be selected) have a higher aspiration level in IS than in RS (where the selection probability is known to be 50\%). This aspirations perspective has the opposite implication (H2) for rich second movers - for instance, one of them explained a zero threshold in IS as follows: "I assume that the first mover would not choose...me... because I already have $50 \mathrm{t}$ [alers]. If he did, I would see it as a bonus so [I] would be satisfied."

${ }^{25}$ Interestingly, two first movers chose the poor and made very low allocations to them. Their rationale was that the poor were "less likely to complain so as to get at least some money", as one of them put it. Both of them did receive complaints.
} 
performance of a selection scheme is the extent to which it induces self-diversions (embezzlement) by the intermediaries. In our experiment, this translates into the question of which design generates higher offers to the second movers. Table 3 shows the average offers made to second movers, computed separately for the two treatments and the two types of second mover.

Table 3. Average allocation to selected second movers

\begin{tabular}{lccc}
\hline & IS & RS & Overall \\
\hline Poor (S1, S2) & 24.1 & 42.3 & 32.9 \\
Rich (S3, S4) & 26.3 & 36.7 & 31.7 \\
\hline Overall & 25.1 & 39.5 & 32.3 \\
\hline
\end{tabular}

We observe strong evidence of increased allocations in RS. Fisher's two-sample permutation test applied to the average offer made by each individual first mover rejects the null hypothesis that offers are independent of the treatment at a significance level of $\alpha=0.001$ (one-sided). ${ }^{26}$

\section{Observation 4. Random selection induces higher offers than selection by intermediaries.}

The higher offers under random selection are consistent with the idea that first movers believe $\mathrm{H} 2$ : expecting less gratitude and more complaints than in IS, they raise their offers in RS. Complaint thresholds were indeed higher on average in RS than in IS, so qualitatively their expectations were met (see above), albeit not by enough to warrant the large increase in first mover offers (as we show now).

We compute the expected payoffs that each first mover would obtain when all role-consistent matchings with pairs of second movers from the set of 60 second movers, occur with equal probability. ${ }^{27}$ In RS, first movers obtain an average expected payoff of 94.5. In IS, expected payoffs are significantly lower with 80.4 (one-sided 1\% level, Fisher's two-sample randomisation test). The first movers pay for overestimating the gratitude effect: their low offers provoke too many complaints. Note also that both figures are below the sure payoff of 100 that a first mover can get by offering 50 to each second mover he selects. ${ }^{28}$ This indicates

\footnotetext{
${ }^{26}$ It is difficult to detect statistical significance for rich and poor recipients separately, because first movers frequently chose one of each kind. Therefore we have to split up the data according to the target beneficiaries (rich/rich, poor/poor, mixed) and this limits the number of data points: in RS, only three such first mover choices are available for the poor/poor and rich/rich cases. Nevertheless, we obtain significantly higher offers (in RS relative to IS) for both mixed and purely poor pairs of active second movers.

${ }^{27}$ These expected payoffs are more informative than the actual payoffs in the experiment, which are affected by luck in the (random) matching of first and second movers. We used simulations to compute these figures, pooling all thresholds from the same role (rich or poor).

${ }^{28}$ Only one first mover (in treatment IS) managed to get an expected payoff higher than 100 (first mover C in session 1 offered 25 each to S3 and S4, generating an expected payoff of 101.3). A first mover aiming to maximise expected payoff should always offer 35 to a rich second mover, and 50 to a poor (and in IS, should
} 
that there is a tendency to underestimate the probability of a complaint (or, less plausibly, a high degree of risk-seeking behaviour). Possibly first movers estimate the likelihood of a single complaint and fail to adjust this to fully take into account the fact that a complaint from just one of the two second movers is sufficient for punishment. ${ }^{29}$ They therefore fail to exercise sufficient precaution given the severity of the punishment. ${ }^{30}$

\subsection{Comparing the effectiveness of the two mechanisms}

A donor is particularly interested in the extent to which the funds are delivered to the needy. With a similar selection distortion and a clear reduction in embezzlement, random selection turns out to be the superior institution in achieving the donor's goals. In our IS treatment, a poor second mover gets an expected allocation of 12.9 talers (weighing the average offer of 24.1 with the $16 / 30$ probability of being selected). When selection is random, this figure rises to 21.2. This is the principal advantage of random selection from the donor's viewpoint.

Furthermore, the rich villagers - who in the village context are still poor in absolute terms can also expect to benefit from random selection. Their expected allocation rises from 12.3 in IS to 18.3 in RS. Thus both poor and rich villagers are better off when the intermediary's selection power is removed.

\section{Summary and conclusions}

We have investigated the comparative performance of two approaches to an important instance of the donor problem. In the first approach, the donor delegates the two tasks of selecting beneficiaries and delivering their benefits, to the same person - the intermediary. In the second approach, the donor separates the two tasks, delegating delivery to the intermediary, but employing a separate actor (who we assume can only select beneficiaries at random) to carry out the selection task.

Our data show that separating the selection task from the delivery task can significantly improve the donor's ability to deliver benefits to the needy. In our data, the distortion caused by having an uninformed party select the beneficiaries is indistinguishable from that caused by opportunism when the intermediary has the power to select; opportunistic intermediaries select the non-needy to reduce the risk of complaints. It is in the delivery task that the

select both rich second movers). This strategy returns 107.7 in IS. In RS, this payoff is 105.3 when giving to two rich second movers, and 104.5 when giving to one rich and one poor.

${ }^{29}$ See Gneezy (1996) for evidence on anchoring and insufficient adjustment in probability estimations. Another possibility is that they only make a point estimate of the complaint threshold distribution and act as if giving this amount would avoid all complaints.

${ }^{30}$ There is no room for learning in one-shot settings, but even if communication, say, increased the coherence of players' beliefs, observations 1 and 2a suggest that this would not undo our results. 
performance of the two approaches part company. Diversion (embezzlement) is significantly reduced when the intermediary is not involved in selection. ${ }^{31}$

The results are consistent with our expectation that villagers are less likely to complain when they feel grateful to the intermediary for selecting them ${ }^{32}$ (and that intermediaries know they can therefore abuse selection power to shirk on delivery). Our controlled experimental setting allowed us to identify the behavioural responses of all the key actors involved in the donor problem. The consistency of their individual behaviours with the mechanics of our motivating arguments makes us sufficiently confident in our results to justify the costs of investigating the effect of task separation in the field settings that confront real-world donors.

The magnitudes of individual behavioural responses and the overall effect of our design adjustment (separating selection and delivery) are bound to depend heavily on context. ${ }^{33}$ So fieldwork is crucial. In-depth field studies could fruitfully investigate the many possible causes of gratitude. The task of gathering reliable data will be onerous, but our experimental results show that there may be significant benefits waiting to be discovered. Ideally, this investigation would use a randomised trial, ${ }^{34}$ along the lines of our experiment. Though it is inherently difficult to recreate a fully controlled environment of the type we have set up in the laboratory, and observability problems often impede the measurement of individual behaviour, careful experimentation may identify the success of different selection institutions in the field. Moreover, a natural experiment could emerge if, for instance, a number of donors changed their target selection policy. Controlling for bias with recent econometric techniques might then permit measuring the impact of delegating selection power to the intermediary.

It is very difficult to gather survey data in a fully reliable manner, but our questionnaire did reveal the role of gratitude and fairness norms in creating the observed distortions. So a carefully designed field survey may help in identifying significant behavioural effects. If these effects fit the behavioural interactions driving our laboratory results, this would further suggest that it is worth paying the costs of a full-fledged randomised trial (and surveys would help solve any practical problems associated with changing the selection institution).

\footnotetext{
31 This is consistent with Olken's (2006) empirical finding (see also Galasso and Ravallion (2005)) that involving local leaders in selection does not improve targeting. However, Olken (2006) does not account for and therefore measure whether local involvement in selection worsens the agency problem of delivery.

${ }^{32}$ Fairness concerns can explain some of our results, but reciprocity (e.g. from gratitude) is needed to explain this impact of the treatment on recipient complaints.

${ }^{33}$ Note that our experiment may under-estimate selection and delivery distortion: first, our anonymous setting allows intermediaries to distinguish rich from poor beneficiaries, but they could not observe individual characteristics affecting propensity to complain; second, bribery options would distort delivery towards the rich since the rich can better afford to bribe.

${ }^{34}$ Under this technique, beneficiary groups are randomly assigned to different treatments of a development project. This method has been increasingly used to evaluate programme effectiveness, in, e.g. health (Miguel and Kremer (2004)), education (Angrist, Bettinger, Bloom, King, and Kremer (2002), Banerjee, Cole, Duflo, and Linden (2005)) and sources of funding (Kremer and Gugerty (2006)). For a general discussion see Duflo and Kremer (2005).
} 
Our results also suggest further experimental research into the donor problem. We focused on the one-shot interaction to capture scenarios where the donor organises a short-term project (such as disaster relief), or a project that only needs seed finance (as with the goats in our first example, whose population is self-sustaining through reproduction). However, it is also common for the donor to provide resources to a fixed village over an extended period of time. In these cases, additional sources of distorted selection may come into play. For instance, villagers may now refrain from complaining out of fear that the intermediary would never select them again - this reinforces our idea that separating selection from delivery may be optimal. ${ }^{35}$ Tackling these issues greatly complicates the framework because of the many additional design questions (e.g. variation in neediness over time, possible replacement of an intermediary caught embezzling or voting over alternative intermediaries). Nonetheless, we believe these dynamic effects present a promising avenue for future research. Our broader hope is that experimental research on the donor problem, by identifying the interaction between selection and delivery as we have done here, can contribute in the effort towards constructing better-designed projects.

\footnotetext{
${ }^{35}$ Villagers may also fear that their complaints will lead the donor to direct its resources elsewhere, abandoning the "problem village". Such fears are reported, e.g. in McIvor (2004).
} 


\section{References}

AbBink, K., and H. Hennig-Schmidt (2002): Neutral versus Loaded Framing in a Bribery Experiment. BonnEcon Discussion Paper 23/2002, University of Bonn.

AbBink, K., B. Irlenbusch, and E. Renner (2002): An Experimental Bribery Game. Journal of Law, Economics, and Organization, 18, 428-454.

AbBINK, K., and S. PEZZINI (2005): Determinants of Revolt: Evidence from Survey and Laboratory Data. Working Paper, CEDEX, University of Nottingham and STICERD/LSE.

Alm, J., G. McClelland, and W. Schulze (1992): Why do people pay taxes? Journal of Public Economics, 48, 2138.

Angrist, J., E. Bettinger, E. Bloom, E. King, and M. Kremer, (2002): Vouchers for Private Schooling in Colombia: Evidence from a Randomized Natural Experiment. American Economic Review, 92, 1535-58.

BALDRY, J. (1986): Tax Evasion Is Not a Gamble - A Report on Two Experiments. Economics Letters, 22, 333-335.

BANERJEE, A. (1997): A Theory of Misgovernance. Quarterly Journal of Economics, 112:4, 1289-1332.

BANERJEe, S. Cole, E. Duflo and L. Linden (2005): Remedying Education: Evidence from Two Randomized Experiments in India, NBER Working Paper, 11904.

BARDhAn, P. (2002): Decentralization of Governance and Development. Journal of Economic Perspectives, 16, $185-205$.

BARDHAn, P., and D. MoOKHERJEe (2000): Capture and Governance at Local and National Levels. American Economic Review, 90, 135-139.

BArdhan, P., and D. MoOKherJeE (2005): Decentralizing AntiPoverty Program Delivery in Developing Countries. Journal of Public Economics, 89:4, 675-704.

BARR, A., and B. KINSEY (2002): Do Men Really have no Shame? Working paper, University of Oxford.

BARR, A., M. Lindelöw, and P. SerneEls (2003): To Serve the Community or Oneself: The Public Servant's Dilemma. Working paper, University of Oxford.

Berg, J., J. Dickhaut, and K. MCCABE (1995): Trust, Reciprocity and Social History. Games and Economic Behavior, 10, 122-142.

Bierschenk, T., J. DE SARDAN, and J. Chauveau (eds) (2000): Courtiers en développement - Les villages africains en quête de projets. Paris: Karthala.

Bolton, G. (1991): A Comparative Model of Bargaining: Theory and Evidence. American Economic Review, 81, 1096-1135.

Bolton, G., and A. OcKenfels (2000): ERC - A Theory of Equity, Reciprocity and Competition. American Economic Review, 90, 166-193.

Brandts, J. and G. Charness (2000): Hot vs. Cold: Sequential Responses and Preference Stability in Experimental Games. Experimental Economics, 2, 227-238.

BRANDTS, J., W. GÜTH, and A. STIEHLER (2006): I Want YOU! An Experiment Studying Motivational Effects when Assigning Distributive Power. Labour Economics, 13:1-17.

BRANDTS, J., T. SAIJO, AND A. SCHRAM (2004): How Universal is Behavior? A Four Country Comparison of Spite, Cooperation and Errors in Voluntary Contribution Mechanisms. Public Choice, 119, 381-424

Burnham, T., K. MCCABE, and V.L. SMith (2000): Friend or Foe: Intentionality Priming in an Extensive Form Trust Game. Journal of Economic Behavior and Organization, 43, 57-74.

CAMERER, C. (2003): Behavioral Game Theory: Experiments on Strategic Interaction. Princeton: Princeton University Press, 2003.

Chabal, P., and J.P. Daloz (1999): Africa Works. Disorder as Political Instrument. Oxford: James Currey.

CHAMBERS, R. (1983): Rural Development: Putting the Last First. Harlow: Longman.

CHARness, G. (2000): Responsibility and Effort in an Experimental Labor Market. Journal of Economic Behavior and Organization, 42, 375-384.

ChARness, G., and M. RABIN (2002): Understanding Social Preferences with Simple Tests. Quarterly Journal of Economics, 117, 817-869.

Conning, J., and Kevane, M. (2002): Community Based Targeting Mechanisms for Social Safety Nets A Critical Review. World Development, 30:3, 375-394.

COX, J., D. Friedman, and V. SADIRAJ (2008): Revealed Altruism. Econometrica, 76:1, 31-69.

Duflo, E., and M. KREMER (2005): Use of Randomization in the Evaluation of Development Effectiveness. Working paper, M.I.T.

FeHR, E., and S. GÄCHTER (2000): Cooperation and Punishment in Public Goods Experiments. American Economic Review 90, 980-994

FEHR, E., and K. SchmidT (1999): A Theory of Fairness, Competition, and Cooperation. Quarterly Journal of Economics, 114, 817-868.

Frank, B., and G. SchUlze (2000): Does Economics make Citizens Corrupt? Journal of Economic Behavior and Organization, 43, 101-113. 
Fuentes, G. (1996): The Use of Village Agents in Rural Credit Delivery. Journal of Development Studies, 33(2), $188-209$.

Galasso, E., and M. Ravallion (2005): Decentralized Targeting of an Anti-Poverty Program. Journal of Public Economics, 89(4), 705-27.

GneEZY, U. (1996): Probability Judgments in Multi-Stage Problems: Experimental Evidence of Systematic Biases, Acta Psychologica, 93, 59-68.

GonZÁLEZ, L., W. GÜTH, and V. LEVATI (2002): Speeding up Bureaucrats by Greasing Them: An Experimental Study. Discussion Paper 05-2002, MPI Jena.

Gugerty, M., and M. Kremer (2006): Outside Funding and the Dynamics of Participation in Community Associations, Working Paper, Poverty Action Lab.

GÜth, W., R. SchmittBerger, and B. Schwarze (1982): An Experimental Analysis of Ultimatum Bargaining. Journal of Economic Behavior and Organization, 3, 367-388.

GÜTH, W., and E. VAN DAMME (1998): Information, Strategic Behavior, and Fairness in Ultimatum Bargaining: An Experimental Study. Journal of Mathematical Psychology, 42, 227-247.

Henrich, J., R. Boyd, S. Bowles, C. CAMErer, E. Fehr, H. Gintis, and R. McElreath (2001): In Search of Homo Oeconomicus: Behavioral Experiments in 15 Small-Scale Societies. American Economic Review, 91: 73-78.

HUMPHREY, S., and A. VERSCHOOR (2004): Decision-making Under Risk Among Small Farmers In East Uganda. Journal of African Economies, 13, 44-101.

JASPARS, S. and H. Young (1995): General Food Distribution in Emergencies: from Nutritional Needs to Political Priorities. Relief and Rehabilitation Network Good Practice Review, No 3, London: Overseas Development Institute.

KESER, C., and F. VAN WINDEN (2000): Conditional Cooperation and Voluntary Contributions to Public Goods. Scandinavian Journal of Economics, 102, 23-39.

KETZIS, J. (1997): Methods for Establishing and Evaluating a Goat Introduction Project. Livestock Research for Rural Development, 9:1.

MCIVOR, C. (2004): Children's feedback committees in Zimbabwe: an experiment in accountability, Humanitarian Practice Network. London: Overseas Development Institute.

Miguel, E., and M. Kremer (2004): Worms: Identifying Impacts on Education and Health in the Presence of Treatment Externalities. Econometrica, 72(1):159-217.

MoIR, R. (1998): A Monte Carlo Analysis of the Fisher Randomization Technique: Reviving Randomization for Experimental Economists. Experimental Economics, 1, 87-100.

OKADA, A., and A. RiEDL (1999): Inefficiency and Social Exclusion in a Coalition Formation Game: Experimental Evidence. Tinbergen Institute discussion paper TI 99-044/1.

OlKEN, A., (2006): Corruption and the costs of redistribution: Micro evidence from Indonesia. Journal of Public Economics, 90, 853-870

OosterbeeK, H., R. Sloof And G. Van De Kuilen, 2004, "Cultural Differences in Ultimatum Game Experiments: Evidence from a Meta-Analysis,"Journal Experimental Economics, 7(2):171-188.

Platteau, J.-P., and A. Abraham (2002): Participatory Development in the Presence of Endogenous Community Imperfections. Journal of Development Studies, 39, 104-36.

Platteau, J.-P., and F. Gaspart (2003): Disciplining Local Leaders in Community-Based Development. Working Paper, University of Namur.

Prendergast, C. (2002): Consumers and Agency Problems. Economic Journal, 112, C34-C51.

Prendergast, C. (2003): The Limits of Bureaucratic Efficiency. Journal of Political Economy, 111, 929-958.

REINIKKA, R. and J. SVENSSON (2005): Fighting Corruption to Improve Schooling: Evidence from a Newspaper Campaign in Uganda, Journal of the European Economic Association, vol. 3(2-3), pages 259-267, 04/05.

ReinikKA, R. and J. Svensson, (2004): Local Capture: Evidence from a Central Government Transfer Program in Uganda. The Quarterly Journal of Economics, 119: 679-705.

Roth, A.E., V. Prasnikar, M. OKUno-FujIWARA, and S. ZAMIR (1991): Bargaining and Market Behavior in Jerusalem, Ljubljana, Pittsburgh, and Tokyo. American Economic Review, 81, 1068-1095.

SElteN, R. (1967): Die Strategiemethode zur Erforschung des eingeschränkt rationalen Verhaltens im Rahmen eines Oligopolexperiments. In Heinz Sauermann (ed.): Beiträge zur experimentellen Wirtschaftsforschung, Vol. I: Tübingen: J.C.B. Mohr (Siebeck), 136-168.

SHLEIFER, A., and R.W. VISHNY (1993): Corruption. Quarterly Journal of Economics, 108, 599-617.

TendLeR, J. (1997): Good Government in the Tropics, Baltimore \& London: Johns Hopkins University Press.

WAdE, R. (1982): The System of Administrative and Political Corruption: Canal Irrigation in South India. Journal of Development Studies, 18:3, 287-328.

WorLD BANK (1996): The World Bank Participation Sourcebook. Washington DC.

WORLD BANK (2002): The World Bank Empowerment Sourcebook. Washington DC. 


\section{Appendix A. The Data}

Table A1. Decisions and matchings in the IS treatment

\begin{tabular}{|c|c|c|c|c|c|c|c|c|c|c|c|c|c|}
\hline \multirow{2}{*}{$\begin{array}{l}\text { Sess- } \\
\text { ion }\end{array}$} & \multirow[b]{2}{*}{ No. } & \multicolumn{4}{|c|}{ First mover } & \multicolumn{2}{|c|}{ S1 } & \multicolumn{2}{|c|}{ S2 } & \multicolumn{2}{|c|}{ S3 } & \multicolumn{2}{|c|}{ S4 } \\
\hline & & $\begin{array}{l}\text { Act- } \\
\text { ive }\end{array}$ & $\begin{array}{l}\text { Alloc } \\
\text { ation }\end{array}$ & $\begin{array}{l}\text { Act- } \\
\text { ive }\end{array}$ & $\begin{array}{l}\text { Alloc } \\
\text { ation }\end{array}$ & IS & RS & IS & RS & IS & RS & IS & RS \\
\hline \multirow{4}{*}{1} & $\mathrm{~A}$ & $\mathrm{~S} 1$ & 30 & S2 & 30 & 0 & 0 & 0 & 30 & 25 & 10 & 50 & 50 \\
\hline & B & S3 & 20 & S4 & 20 & 25 & 25 & 20 & 20 & 0 & 35 & 20 & 30 \\
\hline & $\mathrm{C}$ & S3 & 25 & S4 & 25 & 50 & 40 & 40 & 20 & 0 & 20 & 10 & 10 \\
\hline & $\mathrm{D}$ & $\mathrm{S} 1$ & 20 & $\mathrm{~S} 2$ & 10 & 35 & 30 & 26 & 40 & 0 & 0 & 0 & 33 \\
\hline \multirow{5}{*}{2} & $\mathrm{~A}$ & S1 & 30 & S4 & 20 & 50 & 50 & 35 & 35 & 0 & 20 & 20 & 40 \\
\hline & $\mathrm{B}$ & S1 & 50 & $\mathrm{~S} 2$ & 50 & 40 & 30 & 45 & 45 & 0 & 20 & 10 & 10 \\
\hline & $\mathrm{C}$ & $\mathrm{S} 1$ & 20 & S4 & 20 & 50 & 50 & 30 & 49 & 30 & 30 & 30 & 20 \\
\hline & $\mathrm{D}$ & S1 & 20 & $\mathrm{~S} 2$ & 20 & 40 & 40 & 30 & 0 & 20 & 20 & 0 & 0 \\
\hline & $\mathrm{E}$ & S1 & 5 & $\mathrm{~S} 2$ & 5 & 50 & 50 & 40 & 40 & 33 & 33 & 20 & 20 \\
\hline \multirow{4}{*}{3} & $\mathrm{~A}$ & $\mathrm{~S} 1$ & 20 & S2 & 15 & 0 & 0 & 0 & 0 & 10 & 10 & 10 & 20 \\
\hline & $\mathrm{B}$ & $\mathrm{S} 1$ & 40 & S3 & 10 & 50 & 30 & 25 & 35 & 0 & 50 & 0 & 0 \\
\hline & $\mathrm{C}$ & S3 & 9 & S4 & 9 & 40 & 50 & 20 & 10 & 10 & 10 & 40 & 20 \\
\hline & $\mathrm{D}$ & S3 & 45 & S4 & 45 & 20 & 40 & 50 & 50 & 40 & 30 & 40 & 50 \\
\hline \multirow{2}{*}{7} & $\mathrm{~A}$ & S3 & 45 & $\mathrm{~S} 4$ & 45 & 35 & 30 & 0 & 0 & 0 & 0 & 30 & 40 \\
\hline & $\mathrm{B}$ & $\mathrm{S} 2$ & 20 & S3 & 30 & 30 & 25 & 0 & 10 & 0 & 0 & 30 & 30 \\
\hline
\end{tabular}

Table A2. Decisions and matchings in the RS treatment

\begin{tabular}{|c|c|c|c|c|c|c|c|c|c|c|c|c|c|}
\hline \multirow{2}{*}{$\begin{array}{l}\text { Sess- } \\
\text { ion }\end{array}$} & \multirow[b]{2}{*}{ No. } & \multicolumn{4}{|c|}{ First mover } & \multicolumn{2}{|c|}{ S1 } & \multicolumn{2}{|c|}{ S2 } & \multicolumn{2}{|c|}{$\mathrm{S} 3$} & \multicolumn{2}{|c|}{$\mathrm{S} 4$} \\
\hline & & $\begin{array}{l}\text { Act- } \\
\text { ive }\end{array}$ & $\begin{array}{l}\text { Alloc } \\
\text { ation }\end{array}$ & $\begin{array}{l}\text { Act- } \\
\text { ive }\end{array}$ & $\begin{array}{l}\text { Alloc } \\
\text { ation }\end{array}$ & IS & RS & IS & $\mathrm{RS}$ & IS & RS & IS & RS \\
\hline \multirow{4}{*}{4} & A & $\mathrm{S} 3$ & 50 & $\mathrm{~S} 4$ & 50 & 30 & 0 & 50 & 0 & 50 & 50 & 0 & 0 \\
\hline & B & $\mathrm{S} 1$ & 40 & S3 & 40 & 35 & 25 & 50 & 50 & 15 & 15 & 20 & 20 \\
\hline & $\mathrm{C}$ & $\mathrm{S} 1$ & 50 & $\mathrm{~S} 2$ & 50 & 10 & 15 & 35 & 40 & 50 & 50 & 0 & 0 \\
\hline & $\mathrm{D}$ & $\mathrm{S} 1$ & 35 & S4 & 30 & 20 & 20 & 10 & 0 & 30 & 20 & 0 & 20 \\
\hline \multirow{4}{*}{5} & A & $\mathrm{S} 1$ & 50 & S2 & 50 & 0 & 0 & 0 & 0 & 50 & 50 & 25 & 25 \\
\hline & B & $\mathrm{S} 3$ & 40 & S4 & 40 & 0 & 50 & 20 & 30 & 10 & 30 & 50 & 50 \\
\hline & $\mathrm{C}$ & $\mathrm{S} 2$ & 30 & $\mathrm{~S} 3$ & 30 & 0 & 0 & 20 & 15 & 0 & 0 & 10 & 10 \\
\hline & $\mathrm{D}$ & S2 & 50 & $\mathrm{~S} 4$ & 50 & 40 & 50 & 30 & 30 & 0 & 20 & 20 & 0 \\
\hline \multirow{3}{*}{6} & $\mathrm{~A}$ & S2 & 40 & $\mathrm{~S} 3$ & 30 & 0 & 0 & 35 & 30 & 0 & 0 & 0 & 30 \\
\hline & $\mathrm{B}$ & $\mathrm{S} 1$ & 40 & $\mathrm{~S} 3$ & 10 & 20 & 40 & 20 & 10 & 24 & 22 & 25 & 20 \\
\hline & $\mathrm{C}$ & $\mathrm{S} 2$ & 30 & S4 & 30 & 45 & 37 & 0 & 0 & 20 & 30 & 20 & 30 \\
\hline \multirow{4}{*}{8} & $\mathrm{~A}$ & $\mathrm{~S} 1$ & 50 & $\mathrm{~S} 4$ & 50 & 35 & 30 & 50 & 50 & 25 & 25 & 35 & 35 \\
\hline & $\mathrm{B}$ & S3 & 30 & $\mathrm{~S} 4$ & 30 & 33 & 25 & 39 & 34 & 0 & 0 & 25 & 35 \\
\hline & $\mathrm{C}$ & $\mathrm{S} 1$ & 40 & $\mathrm{~S} 2$ & 40 & 50 & 50 & 0 & 0 & 35 & 35 & 0 & 0 \\
\hline & $\mathrm{D}$ & $\mathrm{S} 2$ & 40 & $\mathrm{~S} 3$ & 40 & 0 & 0 & 40 & 40 & 50 & 50 & 0 & 0 \\
\hline
\end{tabular}




\section{Appendix B: The Instructions for the Experiment}

\section{General information}

We thank you for coming to the experiment. The purpose of this experiment is to study how people make decisions in a particular situation. During the experiment you will earn money. How much money you earn will depend on your decision and on the decisions made by other participants. Payments are confidential, we will not inform any of the other participants of the amount you have earned. In the following, all amounts of money are denominated in talers, the experimental currency unit.

\section{The decision situation}

Each game is played between a group of five players. There are two types of players in each group: one first mover and four second movers, called S1, S2, S3, and S4. The first movers are located in one room, the second movers in a different room in this building. The game is divided into two stages. In the first stage the first mover makes a decision; in the second stage the second mover makes a decision.

At the outset of the experiment, each player has an endowment. This is the sum of money you start with. The endowments are different for different players and are as follows.

\begin{tabular}{cc}
\hline Player & Endowment \\
\hline First mover & 100 \\
Second mover S1 & 0 \\
Second mover S2 & 0 \\
Second mover S3 & 50 \\
Second mover S4 & 50 \\
\hline
\end{tabular}

\section{Stage 1:}

The first mover must decide how many talers s/he allocates to two of the second movers. These two are called the active second movers. How they are selected is described later. The total amount of money available is 100 talers. The first mover receives this money in addition to the endowment mentioned above. The first mover can divide these additional 100 talers among the two active second movers and him/herself in any way. These allocations are added to the players' respective endowments. No money can be allocated to second movers who are not active.

There are two different variants of the game. Half of the experimental groups play each variant. The variants differ in how the two active second movers are determined.

Variant 1: The first mover determines the two active second movers.

Variant 2: The two active second movers are predetermined by a random draw, where each second mover is equally likely to be selected.

Note that only one of the variants is used in this session. 


\section{Stage 2:}

The second movers are located in a different room in the building. At the second stage, each second mover is informed about whether s/he is active, and if so, how much money the first mover has allocated to him/her. No second mover is informed about how much money has been allocated to other second movers, nor how much money the first mover has allocated to $\mathrm{him} /$ herself.

If a second mover is active and has received an allocation of less than 50 talers, s/he can file a complaint. A complaint has the following consequences: First, the payoff of each second mover who files a complaint is reduced by 10 talers. Second, the first mover's payoff is reduced to a final amount of 50 talers (in other words, $\mathrm{s} /$ he loses what $\mathrm{s} /$ he allocated to herself and his/her endowment is reduced from 100 to 50 talers).

If no complaint is filed, the first mover's final payoff is his/her endowment plus the amount s/he has allocated to him/herself. If any complaint is filed, the first mover's final payoff is 50 . A second mover's final payoff is his/her endowment if $\mathrm{s} /$ he is not active. If active, then his/her final payoff is his/her endowment plus the amount the first mover has allocated to him/her minus the above-mentioned complaint costs if $\mathrm{s} / \mathrm{he}$ files a complaint.

\section{How to make decisions}

The first movers and the second movers make their decisions by filling out a decision sheet.

Each first mover is told whether $\mathrm{s} /$ he is in variant 1 or 2 . If in variant $1, \mathrm{~s} /$ he selects exactly two second movers to be the active second movers. Then, in all variants, the first mover decides how to allocate the 100 talers among him/herself and the two active second movers.

Though the game involves two stages, all players make their decisions simultaneously. The second movers decide about the amount below which they will file a complaint, if they are active and a lower amount than this is offered to them. Any number from 0 to 50 is feasible. After all decision sheets are collected, one first mover and one second mover of each type S1, S2, S3, S4 are randomly matched. A complaint is effective if the amount allocated to an active second mover is lower than the number this particular second mover has chosen.

The second movers make decisions for both variants of the game, where the amounts below which they will file a complaint are specified separately for the three variants. Thus, all second movers specify one amount for the case that they have been selected as active by the first mover (variant 1), and one amount for the case that they have been selected randomly (variant 2). Note that both variants are equally likely to be played today.

Note that you specify the amount below which you file a complaint. This means that a 0 in a particular variant means that you will never complain when active in that variant; a 50 means that you will complain unless given at least 50 .

After all decision sheets have been collected, one first mover and one second mover of each type S1, S2, S3, S4 are matched to form a group of five. The decisions are carried out using your decisions for the variant that is played in this session. A complaint is effective if the amount allocated to an active second mover is lower than the number this particular second mover has chosen for this variant.

\section{Payoffs}

At the end of the experiment, the talers are converted into pounds at a rate of $10 \mathrm{p}$ per taler. In addition, every participant receives $£ 4$ for showing up. 


\section{Appendix C: The Post-Experimental Questionnaires}

\section{First Movers, IS Treatment}

We would like you to state your motives for taking the decisions as you did.

(1) Please give your reasons for why you selected the two second movers that you chose.

(2) Why did you choose the particular amounts you allocated to these second movers?

\section{First Movers, RS Treatment}

We would like you to state your motives for taking the decisions as you did.

(1) Why did you choose the particular amounts you allocated to the active second movers?

(2) If you chose to allocate the same amount to each of the second movers, why did you do so? If you chose different amounts, why did you do so?

\section{Second Movers}

We would like you to state your motives for taking the decisions as you did.

(1) Why did you choose the amounts that you chose?

(2) If you chose different amounts for each variant, why did you do so? If you chose the same amounts, why did you do so? 